Article

\title{
Uptake and Distribution of Fenoxanil-Loaded Mesoporous Silica Nanoparticles in Rice Plants
}

\author{
Feng Zhu ${ }^{1,2}{ }^{2}$ Xingang Liu ${ }^{1}$, Lidong Cao ${ }^{1} \mathbb{D}$, Chong Cao $^{1}$, Fengmin Li $^{1}$, Caijun Chen ${ }^{2}$, \\ Chunli $\mathrm{Xu}^{1}{ }^{1}$, Qiliang Huang ${ }^{1, *}$ and Fengpei $\mathrm{Du}^{3, *}$ \\ 1 State Key Laboratory for Biology of Plant Diseases and Insect Pests, Institute of Plant Protection, Chinese \\ Academy of Agricultural Sciences, 2 Yuanmingyuan West Road, Haidian District, Beijing 100193, China; \\ gzzbszf@163.com (F.Z.); liuxingang@caas.cn (X.L.); caolidong@caas.cn (L.C.); ccao@ippcaas.cn (C.C.); \\ fmli@ippcaas.cn (F.L.); springxc12013@126.com (C.X.) \\ 2 Institute of Plant Protection, Guizhou Academy of Agricultural Sciences, Huaxi District, \\ Guiyang 550006, China; chencj1123@126.com \\ 3 Department of Applied Chemistry, College of Science, China Agricultural University, \\ 2 Yuanmingyuan West Road, Haidian District, Beijing 100193, China \\ * Correspondence: qlhuang@ippcaas.cn (Q.H.); dufp@cau.edu.cn (F.D.); \\ Tel.: +86-10-6281-6909 (Q.H.); +86-10-6273-2507 (F.D.)
}

Received: 3 September 2018; Accepted: 17 September 2018; Published: 20 September 2018 updates

\begin{abstract}
Mesoporous silica nanoparticles (MSNs) can be used as carriers to deliver pesticides into plants, which is considered to be one method of improving the efficacy of pesticide usage in agricultural production. In the present work, MSNs with an average diameter of $258.1 \mathrm{~nm}$ were synthesized and loaded with Fenoxanil. The structure of the nanocarriers was observed by scanning electron microscopy. The loading content of Fenoxanil-loaded MSNs was investigated. After rice plants in a hydroponic system were treated with loaded MSNs, the concentrations of Fenoxanil in different samples were determined using high-performance liquid chromatography-tandem mass spectrometry. The results suggested that rice plants can absorb MSNs from water through their roots, and the dosage has almost no effect on the distribution of Fenoxanil in rice plants. The application of pesticide-loaded nanoparticles in a hydroponic system poses a low risk of Fenoxanil accumulation in rice.
\end{abstract}

Keywords: mesoporous silica nanoparticles; Fenoxanil; uptake; distribution; rice

\section{Introduction}

The application of pesticides can be affected by many factors. The main factors include the type and properties of the plants on which the pesticides are used in the field. The uptake and translocation behaviors of pesticides can affect their effectiveness in plants [1]. Pesticides can be classified as systemic or non-systemic, according to their mode of action. Systemic pesticides can be absorbed by plants and transported from the site of application to other parts of the plant, thereby improving the plant's resistance to disease. Once absorbed, systemic pesticides cannot be affected by environmental factors, such as rainfall and climate. They protect the roots from soil insects and soil-borne diseases, while also preventing pests and disease from spreading to the stems and leaves. On the contrary, non-systemic pesticides cannot penetrate into plants when sprayed on their leaves. As they only remain on the surface of plants, they cannot prevent insects from attacking new leaves or the spread of diseases in plant tissues. Different pesticides have different absorption and transmission properties in plants. Previous studies have shown that chlorantraniliprole can be detected in rice stems and leaves after addition to hydroponic culture solution, but it cannot be detected in rice roots after use of the spraying method [2]. The systemic fungicide flumorph shows strong conduction and redistribution to the apical and stratified layers in 
cucumber but has no ability to transport to the roots or between leaves [3]. Although acetoxazole can be transmitted to the substrate in tomato plants, this effect is relatively weak [4]. However, the penflufen can be conducted between the leaves of the plant, with both upward and downward bidirectional conduction characteristics [5]. In general, all pesticides show distinctive absorption and conduction properties in plants. Also, the efficacy of pesticides depends on various factors, such as the plant species, method of application, and period of growth. Therefore, improving the transportation performance of pesticides in plants is an important objective in improving the utilization of pesticides.

Since the first report of an ordered mesoporous material, named MCM-41 by Kresge et al. in 1992, the study of mesoporous silica nanoparticles (MSNs) has received extensive attention [6]. MSNs have good advantages, such as low cost, good environmental compatibility, large specific surface area, adjustable pore size, and high loading capacity. Controlled release of an active compound can be achieved after surface modification, and MSNs are widely used in therapeutics, drug delivery, and diagnostics [7-12]. In recent years, more and more MSNs have been used as pesticide carriers. When pyocyanin was loaded into MSNs to prepare a sustained-release system, the degradation of unstable pyocyanin could be effectively prevented [13]. The application of avermectin in field production has been restricted by time, due to its poor solubility and easy photodegradation. Avermectin-loaded silica nanoparticles demonstrated a remarkable performance, with greatly improved photostability, water solubility, and bioavailability of avermectin $[14,15]$. The cytotoxicity and antibacterial activity of tebuconazole could be improved when MSNs were used as carriers [16]. A sustained antibacterial effect was achieved for volatile essential oils when they were loaded into MSNs [17]. Wanyika et al. loaded MSNs with chlorantraniliprole, and the prepared pesticide-loaded nanoparticles showed a better sustained-release effect [18]. Owing to their good performance, MSNs have been used as vehicles to deliver DNA and chemicals into plants [19]. Mou et al. employed functionalized MSNs to develop an MSN-mediated plant transient gene expression system that carried exogenous DNA into the roots of Arabidopsis thaliana [20]. Zhao et al. conducted a study on the absorption and transport of pesticide-loaded MSNs in cucumbers, and the results indicated that MSNs can be absorbed and transmitted in cucumber after having been applied to the leaves [21,22].

Fenoxanil (CAS No. 115852-48-7, Figure 1) is a new systemic and protective fungicide with residual effects, belonging to the propionamide chemical class. Fenoxanil is a melanin biosynthesis inhibitor used to control rice blast caused by the fungus Pyricularia oryzae [23]. Some researchers have studied Fenoxanil residues [24] and have found that they may exert potentially adverse effects on human health and the environment.

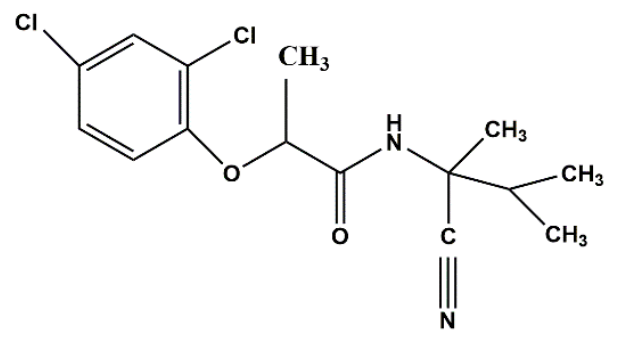

Figure 1. Structure of Fenoxanil.

Rice is grown in many countries and feeds billions of people around the world. However, it is quite susceptible to diseases, of which the most destructive is rice blast, caused by the fungi P. oryzae. It is therefore necessary to prevent rice from fungal diseases that lead to a loss of production, especially rice blast $[25,26]$. Various pesticides are applied to control rice diseases, and good control can be attained. However, adverse effects on humans and the environment may be caused by the low utilization efficiency of pesticide application. Adoption of MSNs as carriers could be a promising solution to some of the limitations modern pesticides are facing.

In the present work, MSNs with an average diameter of $258.1 \mathrm{~nm}$ were synthesized to obtain Fenoxanil-loaded MSNs (Fen@MSNs). Fen@MSNs were then applied to rice plants in order to characterize their uptake and distribution behaviors. Fenoxanil was chosen as the template pesticide, 
since it is widely used to control rice blast. After treatment of the rice plants with Fen@MSNs, the concentrations of Fenoxanil in different plant parts and in environmental samples were determined over a period of 10 days. In addition, the final residue level of Fenoxanil in rice was measured to evaluate the food safety of Fen@MSNs in rice.

\section{Results and Discussion}

\subsection{Preparation and Characterization of MSNs and Fen@MSNs}

In this study, the liquid crystal templating method was used to prepare MSNs, with tetraethyl orthosilicate (TEOS) as the silica precursor and cetyltrimethylammonium bromide (CTAB) as the surfactant in basic conditions. Pesticides were loaded into MSNs by simple immersion in a concentrated methanol solution of Fenoxanil. Because the uptake of MSNs can be affected by their size [27], the morphology of the MSNs and Fen@MSNs was characterized using a scanning electron microscope (SEM) and a transmission electron microscope (TEM). SEM images showed that there was no obvious difference between the MSNs and Fen@MSNs (Figure 2). Both had a monodispersed spherical structure, and their average diameter was $258.1 \mathrm{~nm}$. A histogram of particle size distribution is shown in Figure 3. TEM was applied to evaluate the structure and physical characteristics of the MSNs before and after pesticide loading. In Figure 2a,c, it can be seen that MSNs and Fen@MSNs have similar structures, average diameters, and dispersion, which verifies the SEM results. It can be seen in Figure $2 b$ that there was a highly ordered mesoporous structure, one of the typical structures of MSNs, visible on the surface of the MSNs before Fenoxanil loading. The surface morphology of the Fen@MSNs showed no obvious difference from that of the MSNs (Figure 2d). The mesoporous structure could affect the uptake behaviors of the loaded compounds [28]. In order to evaluate the Fenoxanil loading potential of the MSNs, Brunauer-Emmett-Teller (BET) surface area analysis and Barrett-Joyner-Halenda (BJH) pore size and volume analysis were used to confirm the mesoporous structure of the nanoparticles. After the MSNs were loaded with Fenoxanil, the BET specific surface area decreased sharply from 1356.04 to $642.48 \mathrm{~m}^{2} / \mathrm{g}$. As shown in Figure 4, the type IV isotherm curve of the MSNs increased gradually from 0 to 0.4 P/P0. Compared to MSNs, Fen@MSNs showed an obvious reduction in adsorption capacity and surface area, since most mesoporous pores were blocked by Fenoxanil. This result was confirmed by the Fourier transform infrared (FTIR) spectra (Figure 5), in which the absorption bands at $1673 \mathrm{~cm}^{-1}$ and $1483 \mathrm{~cm}^{-1}$ were attributed to characteristic peaks of Fenoxanil, and the absorption band at $1072 \mathrm{~cm}^{-1}$ was assigned to the MSNs. Both types of absorption bands were observed for Fen@MSNs, confirming that the MSNs were successfully loaded with Fenoxanil.

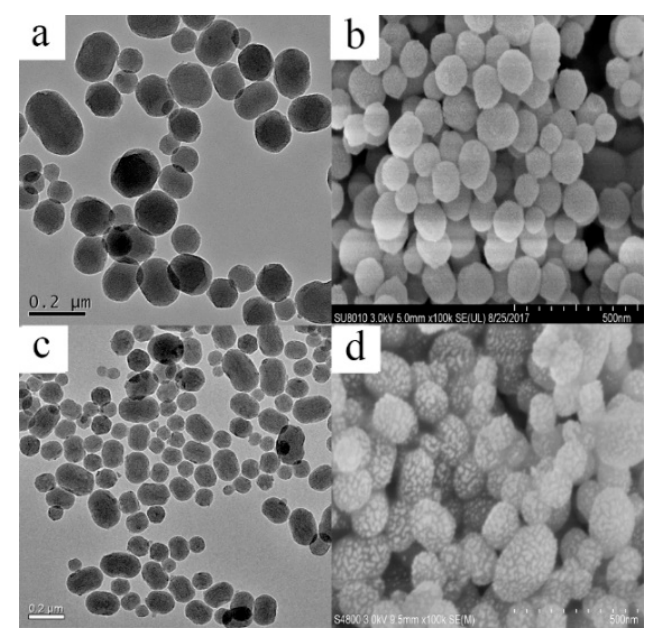

Figure 2. Scanning electron microscope (SEM) images: (a) mesoporous silica nanoparticles (MSNs), scale bar $=0.2 \mu \mathrm{m}$ (c) Fenoxanil-loaded MSNs (Fen@MSNs), scale bar = $500 \mathrm{~nm}$; transmission electron microscope (TEM) images: (b) MSNs, scale bar = $0.2 \mu \mathrm{m}$; (d) Fen@MSNs, scale bar = $500 \mathrm{~nm}$. 


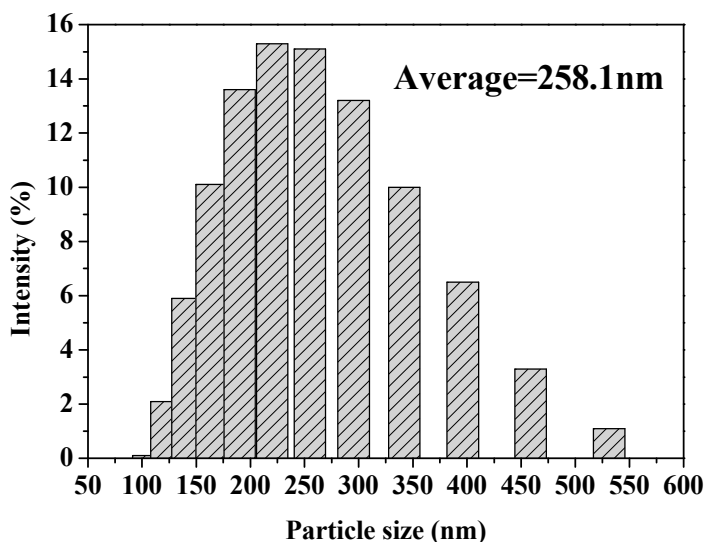

Figure 3. Histogram of the particle size distribution of MSNs.

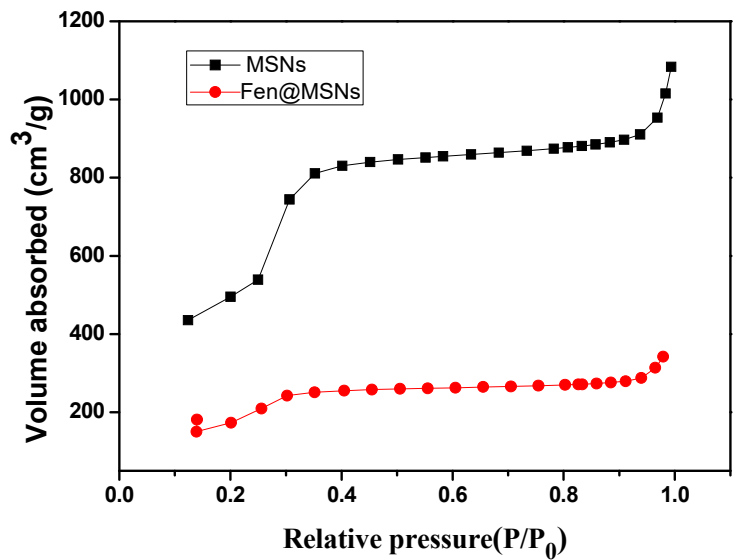

Figure 4. Nitrogen adsorption-desorption isotherms of MSNs and Fen@MSNs.

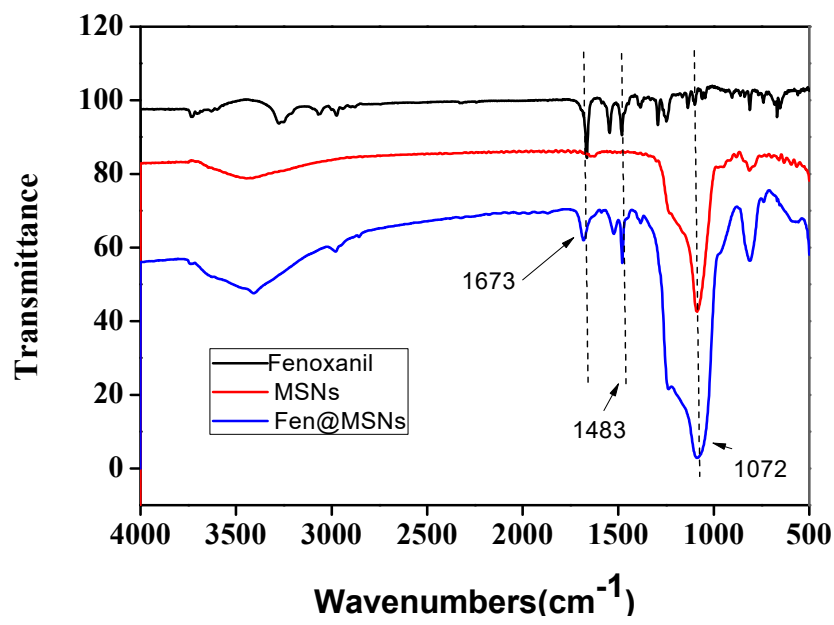

Figure 5. Fourier transform infrared (FTIR) spectra of Fenoxanil, MSNs, and Fen@MSNs.

\subsection{In Vitro Release of Fenoxanil}

The release profiles of Fenoxanil and Fen@MSNs are shown in Figure 6. Because of the poor solubility of Fenoxanil in water, a $20 \%$ aqueous acetonitrile (ACN) solution with Tween-80 emulsifier was used as release medium. After $30 \mathrm{~h}$, the amount of Fenoxanil in the release medium was greater than $50 \%$, and its cumulative release reached nearly $100 \%$ after $100 \mathrm{~h}$. On the contrary, pesticide loaded into MSNs was released slowly, with a cumulative release of about $60 \%$ after $100 \mathrm{~h}$. As shown in Table 1, the cumulative release rates were fitted to three different mathematical models. Comparison of the correlation coefficients $\left(R^{2}\right)$ indicated that the release rates can best be described by the first order 
equation $y=a^{*}\left(1-\exp \left(-b^{*} x\right)\right)$. The present study suggests that MSNs can control the release of Fenoxanil. With the sustained release of the active compound, the effective time can be prolonged to meet the requirements of disease prevention [29].

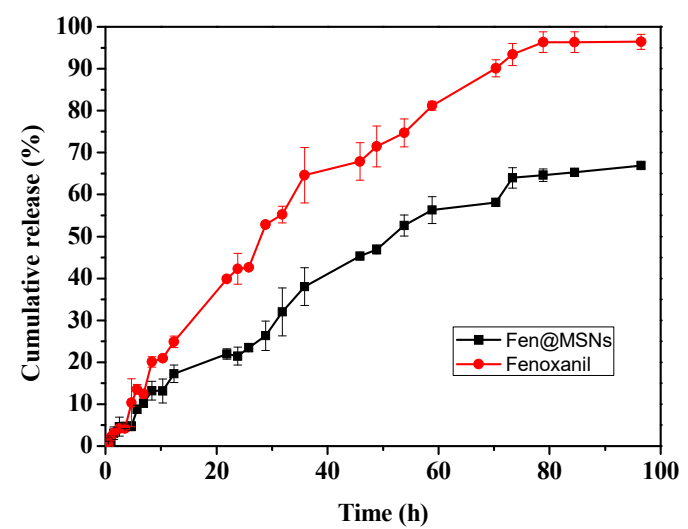

Figure 6. Release rates of Fenoxanil from Fen@MSNs at room temperature.

Table 1. Mathematical models of Fenoxanil release from Fenoxanil and Fen@MSN solutions.

\begin{tabular}{ccccc}
\hline Sample & Models & Equation & Fitting Equation & $\boldsymbol{R}^{\mathbf{2}}$ \\
\hline \multirow{3}{*}{ Fenoxanil } & Zero-order equation & $y=\mathrm{a}+\mathrm{b} x$ & $4.266+1.42 x$ & 0.95371 \\
& First-order equation & $y=\mathrm{a}^{*}\left(1-\exp \left(-\mathrm{b}^{*} x\right)\right)$ & $126.56^{*}\left(1-\exp \left(-0.016^{*} x\right)\right)$ & 0.99416 \\
& Higuchi & $y=\mathrm{a}^{*}\left(x^{\wedge}(1 / 2)\right)+\mathrm{b}$ & $10.725 x^{1 / 2}+0.28305$ & 0.98287 \\
\hline \multirow{3}{*}{ Fen@MSNs } & Zero-order equation & $y=\mathrm{a}+\mathrm{b} x$ & $3.3376+0.77 x$ & 0.98111 \\
& First-order equation & $y=\mathrm{a}^{*}\left(1-\exp \left(-\mathrm{b}^{*} x\right)\right)$ & $89.19^{*}\left(1-\exp \left(-0.015^{*} x\right)\right)$ & 0.99764 \\
& Higuchi & $y=\mathrm{a}^{*}\left(x^{\wedge}(1 / 2)\right)+\mathrm{b}$ & $7.654 x^{1 / 2}-6.6$ & 0.99054 \\
\hline
\end{tabular}

\subsection{Analytical Method Validation}

To eliminate any inaccurate results produced by matrix effects, matrix-matched calibration solutions were used to test the linearity of the method. Matrix-matched calibration solutions were obtained for leaves, roots, stem, rice, soil, and water by preparing blank extracts spiked with different concentrations of Fenoxanil in the range of $0.01-1 \mathrm{mg} / \mathrm{L}$. The quantitative results of the analysis method were mainly dependent on linearity. As shown in Table 2, good linearity was obtained for Fenoxanil with all coefficients of determination $\left(R^{2}\right) \geq 0.9276$. In this study, the recovery amount was measured as a percentage of the amount of Fenoxanil originally spiked to the blank samples. The repeatability of the proposed method was expressed as a relative standard deviation (RSD; $n=5)$. The precision and accuracy of the method was investigated for blank leaf, stem, rice, root, soil, and water samples spiked with Fenoxanil at three different concentrations $(0.01,0.1$ and $1 \mathrm{mg} / \mathrm{kg})$. For each concentration, five spiked tests were repeated for each matrix $(n=5)$. Limits of quantification (LOQs), average recoveries, and relative standard deviations are shown in Table 3. The recoveries of Fenoxanil were in the range of $77-110 \%$ for all the samples, and RSDs were no greater than $10 \%$ for all cases. LOQs were determined as the lowest concentration of Fenoxanil detected by the instrument. 
Table 2. The standard calibration curve $\left(R^{2}\right)$, limit of detection (LOD), and limit of quantification (LOQ) of Fenoxanil in different matrices.

\begin{tabular}{cccccc}
\hline \multirow{2}{*}{ Compound } & Matrix & \multicolumn{2}{c}{ Standard Calibration Curve } & \multirow{2}{*}{ LOD (mg/kg) } & \multirow{2}{*}{ LOQ (mg/kg) } \\
\cline { 3 - 4 } & & Regression Equation & $\boldsymbol{R}^{\mathbf{2}}$ & & \\
\hline \multirow{4}{*}{ Fenoxanil } & roots & $y=588191 x+14086$ & 0.9968 & 0.0001 & 0.001 \\
& stem & $y=536119 x+11018$ & 0.9997 & 0.0001 & 0.001 \\
& rice & $y=513143 x+11661$ & 0.9938 & 0.0001 & 0.001 \\
& leaves & $y=383365 x+15639$ & 0.97 & 0.0001 & 0.001 \\
& soil & $y=565884 x+12994$ & 0.9985 & 0.0001 & 0.001 \\
& water & $y=529117 x+33323$ & 0.9276 & 0.0001 & 0.001 \\
\hline
\end{tabular}

Table 3. Accuracy and precision of the analysis method in different matrices at three levels of spiked Fenoxanil.

\begin{tabular}{|c|c|c|c|c|}
\hline Sample & Spiked Level (mg/kg) & Average Recoveries (\%) & RSD (\%) & LOQ (mg/kg) \\
\hline \multirow{3}{*}{ Roots } & 1.0 & 85 & 3 & \multirow{3}{*}{0.001} \\
\hline & 0.1 & 101 & 6 & \\
\hline & 0.01 & 89 & 4 & \\
\hline \multirow{3}{*}{ Leaves } & 1.0 & 79 & 2 & \multirow{3}{*}{0.001} \\
\hline & 0.1 & 95 & 6 & \\
\hline & 0.01 & 88 & 7 & \\
\hline \multirow{3}{*}{ Stems } & 1.0 & 87 & 9 & \multirow{3}{*}{0.001} \\
\hline & 0.1 & 90 & 3 & \\
\hline & 0.01 & 105 & 6 & \\
\hline \multirow{3}{*}{ Rice } & 1.0 & 88 & 8 & \multirow{3}{*}{0.001} \\
\hline & 0.1 & 79 & 4 & \\
\hline & 0.01 & 99 & 7 & \\
\hline \multirow{3}{*}{ Water } & 1.0 & 92 & 7 & \multirow{3}{*}{0.001} \\
\hline & 0.1 & 78 & 9 & \\
\hline & 0.01 & 102 & 8 & \\
\hline \multirow{3}{*}{ Soil } & 1.0 & 91 & 4 & \multirow{3}{*}{0.001} \\
\hline & 0.1 & 77 & 5 & \\
\hline & 0.01 & 110 & 8 & \\
\hline
\end{tabular}

\subsection{Translocation of Fluorescein Isothiocyanate (FITC)-Labeled MSNs in Rice Plants}

To study the uptake of MSNs from water, their distribution through the roots, and their delivery to the leaves, rice plants were grown in a hydroponic system. MSNs were labeled with FITC to make them visible under a laser scanning microscope (LSM). It was found that FITC-labeled MSNs could be quickly absorbed by roots from water, transported to the stems, and then transferred to the leaves. This demonstrates that, in rice plants, Fenoxanil can be carried by MSNs from the site of delivery to other tissues. These results are similar to those reported by Nair et al., who showed that FITC-labeled MSNs could be absorbed quickly by rice seedlings [30]. As seen from the LSM images of blank and treated rice samples (Figure 7), the green dot are FITC-labeled MSNs were found in rice leaves as shown in Figure 7a,b, but were not detected in blank rice plants. As it has been previously reported that MSNs can be transported in plants and can carry active compounds to different tissues [31,32] MSNs might be able to enter the plant from the surface of leaves [15], then be transported in both vessels and sieve tubes, and finally be distributed to various parts of the plant. No adverse effects were observed in the rice grown in the hydroponic system containing the suspension of FITC-labeled MSNs. 


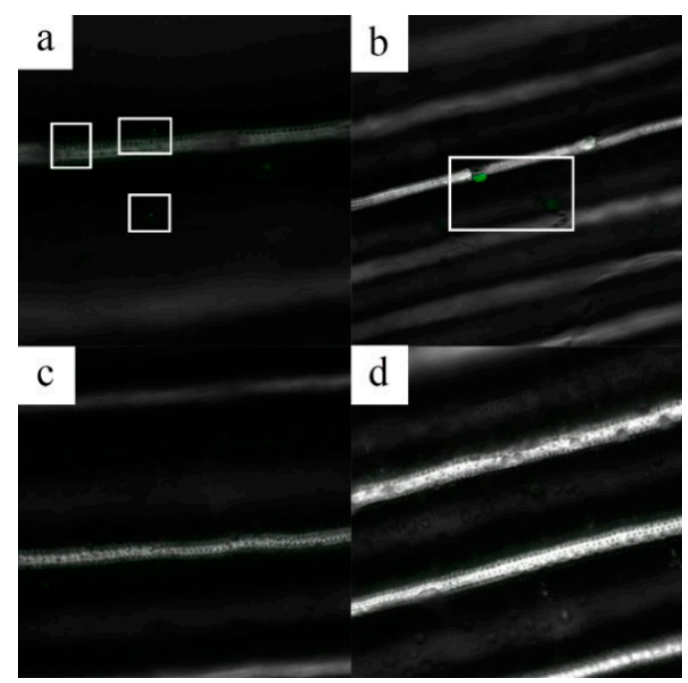

Figure 7. Laser scanning microscopy (LSM) images of rice plants $24 \mathrm{~h}$ after MSN-fluorescein isothiocyanate (FITC) treatment. (a) Treated plant; (b) Treated plant (c) Blank plant; (d) Blank plant

\subsection{Uptake and Distribution of Fenoxanil-Loaded Mesoporous Silica Nanoparticles in Rice plants}

The results of the present study demonstrated that the uptake and distribution of Fenoxanil-loaded MSNs within various tissues of rice plants and environmental substrates, i.e., the roots, stem, leaves, soil, and water, is possible. It can be seen in Figure 8a,b that the concentration of Fenoxanil in the roots increased from 0.04 to $0.11 \mathrm{mg} / \mathrm{kg}$ from $2 \mathrm{~h}$ to 10 days post-treatment. Similarly, in the leaves and soil, the concentration of Fenoxanil increased gradually, as shown in Figure 8e-h. On the contrary, the concentration of Fenoxanil decreased over time in the water. In the stems, the concentration of Fenoxanil increased until day five of sampling and then decreased. This shows that the uptake and retention of Fen@MSNs might vary across different rice tissues and environmental samples. In this study, the uptake and distribution behavior of Fen@MSNs in rice plants was examined at two dosages of Fenoxanil ( 30 and $50 \mathrm{mg} / \mathrm{L}$ ). Generally, the concentrations of Fenoxanil in the samples were higher when $50 \mathrm{mg} / \mathrm{L}$ of Fenoxanil was used compared to $30 \mathrm{mg} / \mathrm{L}$ of Fenoxanil (Figure 8). However, there were no obvious differences in the distribution patterns of the pesticide between the 30 and $50 \mathrm{mg} / \mathrm{L}$ treatments, which showed that the dosage had no effect on the distribution of Fen@MSNs in rice plants. 

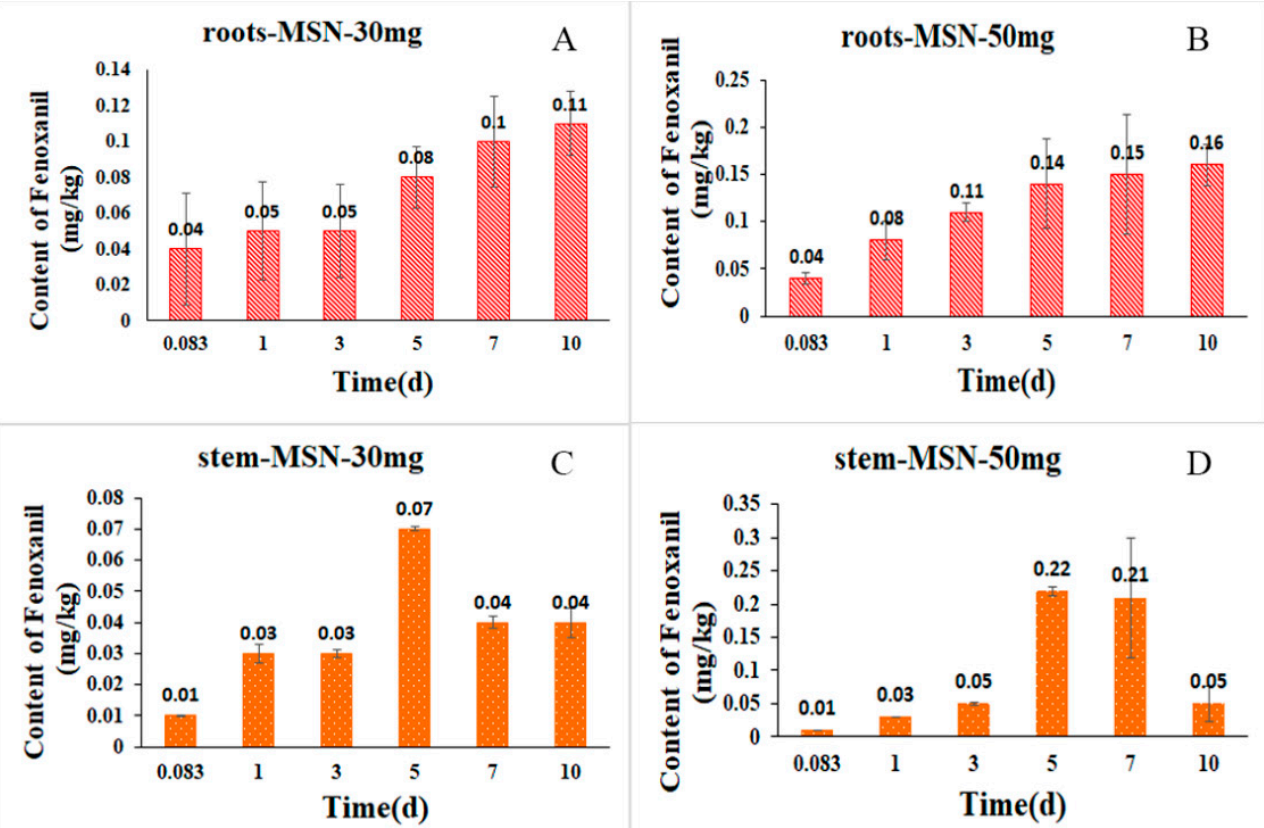

stem-MSN-50mg D
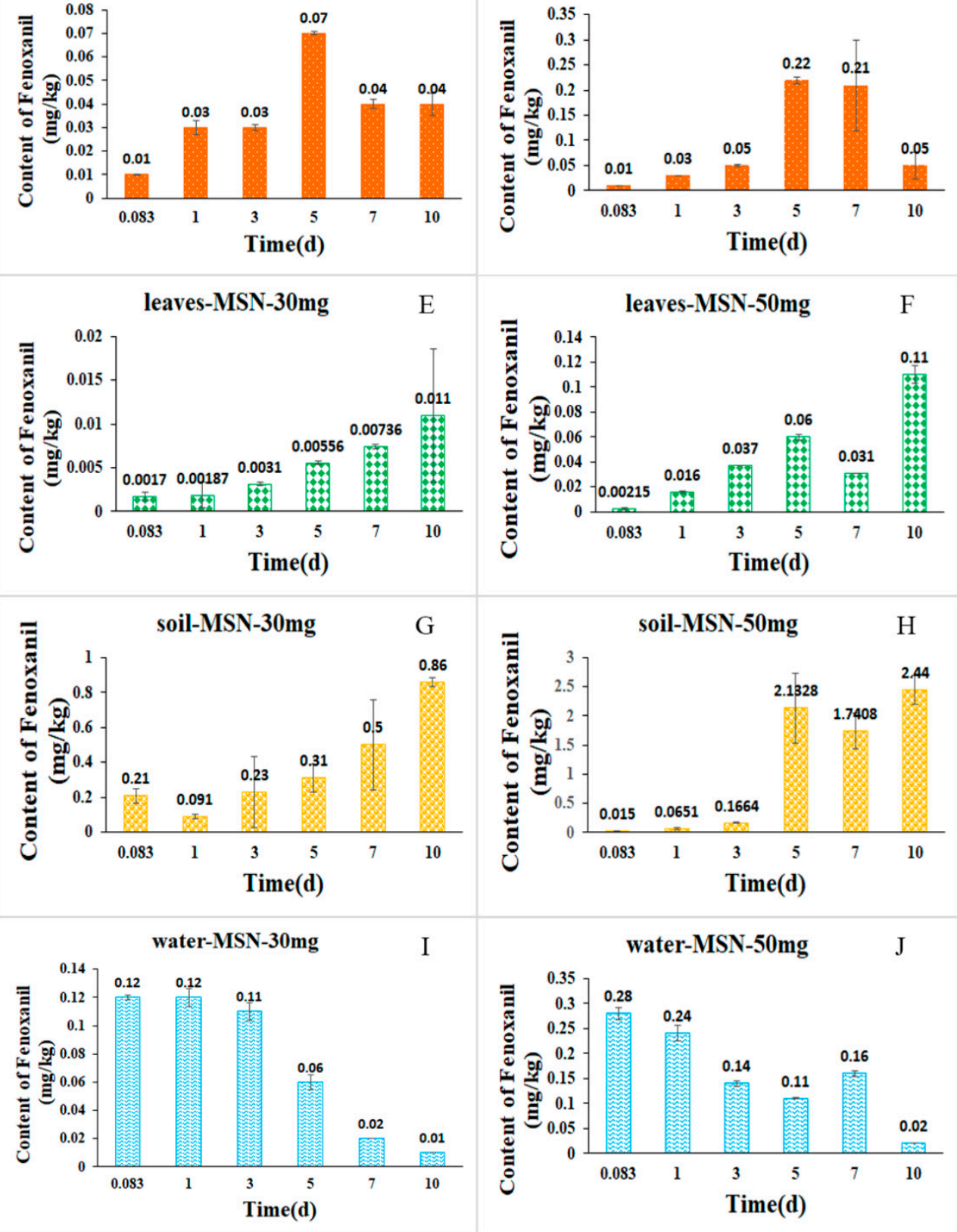

Figure 8. Distribution of Fennoxanil in rice plants: (A) roots with $30 \mathrm{mg} / \mathrm{L}$ treatment; (B) roots with $50 \mathrm{mg} / \mathrm{L}$ treatment; (C) stem with $30 \mathrm{mg} / \mathrm{L}$ treatment; (D) stem with $50 \mathrm{mg} / \mathrm{L}$ treatment; (E) leaves with $30 \mathrm{mg} / \mathrm{L}$ treatment; (F) leaves with $50 \mathrm{mg} / \mathrm{L}$ treatment; $(\mathbf{G})$ soil with $30 \mathrm{mg} / \mathrm{L}$ treatment; (H) soil with $50 \mathrm{mg} / \mathrm{L}$ treatment; (I) water with $30 \mathrm{mg} / \mathrm{L}$ treatment; (J) water with $50 \mathrm{mg} / \mathrm{L}$ treatment. 


\subsection{Final Residues of Fenoxanil in Rice}

The results showed that the final concentrations of Fenoxanil residue in rice were lower than $0.001 \mathrm{mg} / \mathrm{kg}$. The maximum residue limit (MRL) for Fenoxanil in rice is $1 \mathrm{mg} / \mathrm{kg}$ in both China and Japan. Obviously, the Fenoxanil residues in rice were under the MRL value after the rice plants were treated by Fenoxanil-loaded MSNs. This suggests that the delivery of Fenoxanil into rice by MSNs poses only a low risk of residual Fenoxanil accumulation.

\section{Materials and Methods}

\subsection{Materials}

Fenoxanil (92.5\%) was provided by Jiangsu Changqing Agrochemical Co., Ltd. CTAB (99\%) was obtained from J\&K Scientific Ltd. (Beijing, China). TEOS (99\%) was purchased from Fluorochem Ltd. (Hadfield, UK). Deionized water was obtained from a Milli-Q water purification system from Millipore (Burlington, MA, USA). Primary secondary amine (PSA) and graphitized carbon black (GCB) were purchased from Agela Technologies (Tianjin, China). All other chemicals and reagents were commercially available and used as received without further purification.

\subsection{Synthesis and Characterization of Mesoporous Silica Nanoparticles}

A volume of $480 \mathrm{~mL}$ of deionized water was used to dissolve $1.0 \mathrm{~g}$ of CTAB. Under constant stirring, $3.5 \mathrm{~mL}$ of sodium hydroxide $(2.0 \mathrm{M})$ was then added to the CTAB solution at room temperature. After the temperature of the solution reached $70{ }^{\circ} \mathrm{C}$ in an oil bath, $5.0 \mathrm{~mL}$ of TEOS was added to the mixture in a dropwise manner at the rate of $1.0 \mathrm{~mL} / \mathrm{min}$. The solution was then stirred vigorously at $80{ }^{\circ} \mathrm{C}$ for $6 \mathrm{~h}$. This process resulted in the formation of white MSNs solid particles, which were then washed three times each with ethanol and deionized water and subsequently freeze-dried under a vacuum. To remove the surfactant, the synthesized MSNs were calcined at $550{ }^{\circ} \mathrm{C}$ for $6 \mathrm{~h}$. Electron microscopy studies were carried out with an SEM (SU8000; Hitachi Ltd.; Tokyo, Japan) and a TEM (JEM-200CX; Jeol Ltd., Tokyo, Japan) in order to study the structural and morphological features of Fen@MSNs and MSNs. The particle size of MSNs was analyzed by dynamic light scattering (DLS) (Malvern Z90; Malvern Instruments, Malvern, UK). The Fourier transform infrared (FT-IR) spectra of the samples were recorded with an FTIR spectrometer (NICOLET 6700; Thermo Scientific; Waltham, MA, USA) with a potassium bromide pellet. Spectra were recorded over the spectral region of 400 to $4000 \mathrm{~cm}^{-1}$ at a spectral resolution of $4 \mathrm{~cm}^{-1}$. In order to examine their pore characteristics, the nitrogen adsorption of MSNs and Fen@MSNs was studied using a surface area and pore size analyzer (TriStarII 3020; Micromeritics Instruments Corporation; Norcross, GA, USA) at $196{ }^{\circ} \mathrm{C}$. Samples were degassed at $80^{\circ} \mathrm{C}$ for $12 \mathrm{~h}$ prior to analysis. The mesoporous structure characteristics were analyzed using the $\mathrm{BET}$ and $\mathrm{BJH}$ procedures applied to the adsorption branches of the isotherms.

\subsection{Loading of Fenoxanil into Mesoporous Silica Nanoparticles}

Synthetic MSNs (300 mg) were added into the Fenoxanil-methanol solution $(4.0 \mathrm{mg} / \mathrm{mL}, 11.5 \mathrm{~mL})$. The mixture was ultrasonicated for $35 \mathrm{~min}$, and then centrifuged at 10,000 rpm for $10 \mathrm{~min}$ to remove the supernatant. The Fenoxanil-loaded MSNs were dried at $50{ }^{\circ} \mathrm{C}$ for $5 \mathrm{~h}$ to remove the supernatant completely. The loading efficiency of Fenoxanil was measured by high-performance liquid chromatography (HPLC) using a 1200-DAD (Diode Array Detector; Agilent; Santa Clara, CA, USA). In brief, $40 \mathrm{mg}$ of Fen@MSNs were dissolved in $10.0 \mathrm{~mL}$ of acetonitrile under sonication for $20 \mathrm{~min}$, then subject to centrifugation at 10,000 rpm for $5 \mathrm{~min}$, after which the supernatant was put into a volumetric flask. This process was repeated several times, and the acetonitrile solution was combined for HPLC analysis. For the HPLC analysis, a Venusil XBP-C18 column $(2.5 \mathrm{~mm} \times 4.6 \mathrm{~mm}$, $5 \mu \mathrm{m}$; Bonna-Agela Technologies Inc.; Tianjin, China) was used to separate the target compound from others at $30^{\circ} \mathrm{C}$. Acetonitrile/water (70:30) was used as mobile phase at a flow rate of $1.0 \mathrm{~mL} / \mathrm{min}$. DAD signals were recorded at $230 \mathrm{~nm}$. The loading efficiency (\%) was calculated as (weight of 
pesticide in nanoparticles / weight of nanoparticles) $\times 100 \%$. In this study, the loading efficiency of MSNs was $14.8 \%$.

\subsection{Synthesis of FITC-labeled MSNs}

To make the MSNs visible in rice plants, they were labeled with FITC. A total of $500 \mathrm{mg}$ of MSNs were added to $40 \mathrm{~mL}$ of methylbenzene and, after ultrasonic dispersion for $15 \mathrm{~min}$, the suspension was heated to $80^{\circ} \mathrm{C}$ under vigorous stirring. Later, $100 \mu \mathrm{L}$ of (3-Aminopropyl)triethoxysilane (APTES) was introduced into the suspension and the sample was prepared by refluxing at $110^{\circ} \mathrm{C}$. To remove excess APTES, the MSNs were washed three times with water and ethanol. Subsequently, $150 \mathrm{mg}$ of FITC was dissolved in $150 \mathrm{~mL}$ of ethanol. The mixture was magnetically stirred vigorously for $24 \mathrm{~h}$ at room temperature to cross connect the APTES and the FITC. The FITC-labeled MSNs were washed three times with ethanol and deionized water to remove excess FITC, centrifuged at 10,000 rpm for $3 \mathrm{~min}$, and then freeze-dried. To prevent the fluorescence intensity from decreasing, the prepared nanoparticles were covered with aluminum foil and stored at $4{ }^{\circ} \mathrm{C}$.

\subsection{Fenoxanil Release}

Fen@MSNs $(20 \mathrm{mg})$ were dispersed in $250 \mathrm{~mL}$ of phosphate buffer $(\mathrm{pH}=6.93)$ containing $0.1 \%$ Tween-80 emulsifier, which was used as the release medium. A D-800LS dissolution tester (Tianjin University, Tianjin, China) was used for the release test at a stirring speed of $120 \mathrm{rpm}$. In order to verify the sustained release property of Fen@MSNs, the cumulative release rate of Fenoxanil from the nanoparticles was calculated by measuring its concentration in the release medium. For HPLC analysis, $0.8 \mathrm{~mL}$ of the release medium was withdrawn from the assay at given time intervals. It was replaced with an equal volume of Tween- 80 containing phosphate buffer, in order to maintain a constant volume of assay solution. The release test was performed duplicates. The accumulative release can be calculated by the following equation:

$$
E_{r}=\frac{V e \sum_{1}^{n-1} C_{i}+V_{0} C_{n}}{M_{p}} \times 10
$$

$E_{r}$ : the accumulative release (\%) of Fenoxanil from the nanoparticles;

$V e$ : the volume of the release medium taken in a time interval $(V e=0.8 \mathrm{~mL})$;

$C_{i}$ : the Fenoxanil concentration in the release medium;

$i$ : the release time

$V_{0}$ : the volume of the release medium $(250 \mathrm{~mL})$;

$n$ : the sample number;

$M_{p}$ : the total amount of pesticide entrapped in the nanoparticles.

\subsection{Greenhouse Study}

Rice plants were cultivated in pools made of concrete and potting soil. The Fen@MSNs were weighed and added into the pool at the heading period of rice growth. Two concentration levels of Fenoxanil were used for the uptake and distribution study: $30 \mathrm{mg} / \mathrm{L}$ and $50 \mathrm{mg} / \mathrm{L}$ (The different amounts of Fen@MSNs corresponding to both $30 \mathrm{mg} / \mathrm{L}$ and $50 \mathrm{mg} / \mathrm{L}$ total Fenoxanil.). In order to characterize the uptake and distribution behavior of Fenoxanil in rice plants during different growth durations, representative samples were collected $2 \mathrm{~h}, 1,3,5,7$, and 10 days after the application of Fen@MSNs. Each treatment was repeated three times. The Fenoxanil concentration in the roots, leaves, and stems of the rice plants, as well as in the paddy water and paddy soil were determined over a period of 10 days using high-performance liquid chromatography-tandem mass spectrometry (HPLC-MS/MS). The concentration levels of Fenoxanil in rice were also determined during the harvest time. 


\subsection{Sample Preparation}

Homogenized sample aliquots $(2 \pm 0.1 \mathrm{~g})$ were weighed and each was added to a $50-\mathrm{mL}$ polypropylene screw-cap centrifuge tube. For validation of the recovery studies, negative controls were prepared by adding an appropriate volume of working standard solution to blank samples. The tubes containing the target samples were incubated for $2 \mathrm{~h}$ at room temperature to distribute the pesticide evenly. Ultrapure water $(5 \mathrm{~mL})$ and acetonitrile $(10 \mathrm{~mL})$ were then added to these samples, and the tubes were shaken vigorously at an oscillation frequency of $1350 \mathrm{~min}^{-1}$ for $10 \mathrm{~min}$ using a CK-2000 high-throughput grinder (TH Morgan, Beijing, China). Subsequently, $1 \mathrm{~g}$ of NaCl and $4 \mathrm{~g}$ of anhydrous $\mathrm{MgSO} 4$ were added. The tubes were immediately shaken again for $5 \mathrm{~min}$ and then centrifuged for $5 \mathrm{~min}$ at a relative centrifugal force (RCF) of $2811 \times g$ using a SIGMA 3-15 centrifuge (SIGMA, Taufkirchen, Germany). After extraction, $1.5 \mathrm{~mL}$ of the supernatant was transferred into a single-use centrifuge tube containing $20 \mathrm{mg}$ of GCB and $30 \mathrm{mg}$ of PSA. The samples were then vortexed for $1 \mathrm{~min}$ and centrifuged for $5 \mathrm{~min}$ at an RCF of $2400 \times \mathrm{g}$. The upper layer was filtered through a $0.22-\mu \mathrm{m}$ nylon syringe filter into an auto-sampler vial for HPLC-MS/MS injection. Matrix-matched standard solutions were used to eliminate any possible matrix effects. The retention time of Fenoxanil was $5.05 \mathrm{~min}$. Two ion transitions were chosen: $m / z 328 \rightarrow 189$ (quantification), and $m / z 328 \rightarrow 302$ (confirmation). ACN and formic acid water $(v / v=0.1 \%$ ) were chosen for the mobile phase, the flow gradients were: $35 \% \mathrm{ACN}$ and $65 \%$ water at $0 \mathrm{~min} ; 85 \% \mathrm{ACN}$ and $15 \%$ water at $1.8 \mathrm{~min} ; 35 \% \mathrm{ACN}$ and $65 \%$ water at $6.5 \mathrm{~min}$; and $35 \% \mathrm{ACN}$ and $65 \%$ water at $7 \mathrm{~min}$.

\section{Conclusions}

Numerous studies have shown that MSNs can be used as carriers to deliver pesticides into plants. This is considered to be an effective method of reducing the amount of pesticide used. However, this new method raises significant concerns about its behavior in plants. The uptake and distribution behavior of nanoparticles in plants needs to be uncovered before the method can be widely applied in the field. In this study, Fen@MSNs were synthesized and used on rice. It was shown that Fen@MSNs can be delivered to and absorbed by rice plants, and the dosage has almost no effect on the distribution of Fen@MSNs in rice plants. The results also suggest that the distribution behavior of pesticides in plants could be regulated by MSNs. The application of Fen@MSNs in water carries only a low risk of Fenoxanil accumulating in the edible part of the plant. This work can help us understand the effects of nanopesticides when used on plants. It provides insight into the fate of Fen@MSNs in different samples in hydroponic system.

Author Contributions: For research articles with several authors, a short paragraph specifying their individual contributions must be provided. The following statements should be used "Conceptualization, Q.H. and F.D.; Methodology, L.C.; Software, C.C. (Chong Cao); Validation, L.C., C.C. (Caijun Chen) and X.L.; Formal Analysis, F.Z.; Investigation, C.X. and F.Z.; Resources, F.L. and C.C. (Chong Cao); Data Curation, C.X.; Writing-Original Draft Preparation, F.Z.; Writing-Review \& Editing, F.Z.; Visualization, F.Z.; Supervision, Q.H.; Project Administration, L.C.; Funding Acquisition, Q.H. and F.Z.".

Funding: This work was supported by the National Key R\&D Program of China (No. 2017YFD0200302) and the State Key Laboratory for Biology of Plant Disease and Insect Pests (No. SKL0F201711).

Conflicts of Interest: The authors declare no conflict of interest.

\section{Abbreviations}

$\begin{array}{ll}\text { MSNs } & \text { mesoporous silica nanoparticles } \\ \text { Fen@MSNs } & \text { Fenoxanil-loaded MSNs } \\ \text { CTAB } & \text { cetyltrimethylammonium bromide } \\ \text { PSA } & \text { primary secondary amine } \\ \text { GCB } & \text { graphitized carbon black } \\ \text { FITC } & \text { fluorescein isothiocyanate } \\ \text { APTES } & \text { (3-Aminopropyl)triethoxysilane } \\ \text { SEM } & \text { scanning electron microscope }\end{array}$




$\begin{array}{ll}\text { TEM } & \text { transmission electron microscope } \\ \text { BET } & \text { Brunauer-Emmett-Teller } \\ \text { BJH } & \text { Barrett-Joyner-Halenda } \\ \text { DLS } & \text { dynamic light scattering } \\ \text { FTIR } & \text { Fourier transform infrared } \\ \text { DAD } & \text { diode array detector } \\ \text { HPLC } & \text { high-performance liquid chromatography } \\ \text { HPLC-MS/MS } & \text { high-performance liquid chromatography-tandem mass spectrometry } \\ \text { RSD } & \text { relative standard deviation } \\ \text { LOD } & \text { limit of detection } \\ \text { LOQ } & \text { limit of quantification } \\ \text { LSM } & \text { laser scanning microscope } \\ \text { MRL } & \text { maximum residue limit }\end{array}$

\section{References}

1. Stamm, M.D.; Heng-Moss, T.M.; Baxendale, F.P.; Siegfried, B.D.; Blankenship, E.E.; Nauen, R. Uptake and translocation of imidacloprid, clothianidin and flupyradifurone in seed-treated soybeans. Pest Manag. Sci. 2016, 72, 1099-1109. [CrossRef] [PubMed]

2. Wu, Y.E.; Li, J.; Zheng, K.M.; Wang, D.P.; Wang, X.B.; Zhang, Y.P.; Xue, W.; Hu, D.Y. The systemic properties of chlorantraniliprole in rice plant by UPLC-HRMS. Agrochemicals 2017, 56, 176-179.

3. Zhu, S.S.; Liu, X.L.; Li, J.Q.; Si, N.G. Uptake and translocation behavior of new fungicide flumorph in cucumber plant. Chem. J. Chin. Univ. 2006, 27, 1887-1890.

4. Chen, F.P.; Han, P.; Liu, J.L.; Si, N.G.; Wang, Y.H.; Liu, P.F.; Liu, X.L. Study on the systemic properties of SYP-Z048 in tomato seedling using high performance liquid chromatography. Chin. J. Pestic. Sci. 2014, 16, 144-152.

5. Han, P.; Hu, B.; Ma, S.; Cao, Y.S. Evaluation of systemic properties of penflufen in wheat seedling using ultra performance liquid chromatography-tandem mass spectrometry method. Chin. J. Pestic. Sci. 2017, 19, 729-734.

6. $\quad$ Kresge, C.T.; Leonowicz, M.E.; Roth, W.J.; Vartuli, J.C.; Beck, J.S. Ordered mesoporous molecular sieves synthesized by a liquid-crystal template mechanism. Nature 1992, 359, 710-712. [CrossRef]

7. Kuthati, Y.; Kankala, R.K.; Lin, S.X.; Weng, C.F.; Lee, C.H. pH-Triggered Controllable Release of Silver-Indole-3 Acetic Acid Complexes from Mesoporous Silica Nanoparticles (IBN-4) for Effectively Killing Malignant Bacteria. Mol. Pharm. 2015, 12, 2289-2304. [CrossRef] [PubMed]

8. Kuthati, Y.; Kankala, R.K.; Busa, P.; Lin, S.X.; Deng, J.P.; Mou, C.Y.; Lee, C.H. Phototherapeutic spectrum expansion through synergistic effect of mesoporous silica trio-nanohybrids against antibiotic-resistant gram-negative bacterium. J. Photochem. Photobiol. B 2017, 169, 124-133. [CrossRef] [PubMed]

9. Kankala, R.K.; Liu, C.G.; Chen, A.Z.; Wang, S.B.; Xu, P.Y.; Mende, L.K.; Liu, C.L.; Lee, C.H.; $\mathrm{Hu}$, Y.F. Overcoming Multidrug Resistance through the Synergistic Effects of Hierarchical pH-Sensitive, ROS-Generating Nanoreactors. ACS Biomater. Sci. Eng. 2017, 3, 2431-2442. [CrossRef]

10. Kankala, R.K.; Kuthati, Y.; Liu, C.L.; Mou, C.Y.; Lee, C.H. Killing cancer cells by delivering a nanoreactor for inhibition of catalase and catalytically enhancing intracellular levels of ROS. RSC Adv. 2015, 5, 86072-86081. [CrossRef]

11. Hung, B.Y.; Kuthati, Y.; Kankala, R.K.; Kankala, S.; Deng, J.P.; Liu, C.L.; Lee, C.H. Utilization of Enzyme-Immobilized Mesoporous Silica Nanocontainers (IBN-4) in Prodrug-Activated Cancer Theranostics. Nanomaterials 2015, 5, 2169-2191. [CrossRef] [PubMed]

12. Huang, P.K.; Lin, S.X.; Tsai, M.J.; Leong, M.K.; Lin, S.R.; Kankala, R.K.; Lee, C.H.; Weng, C.F. Encapsulation of 16-Hydroxycleroda-3,13-Dine-16,15-Olide in Mesoporous Silica Nanoparticles as a Natural Dipeptidyl Peptidase-4 Inhibitor Potentiated Hypoglycemia in Diabetic Mice. Nanomaterials 2017, 7, 112. [CrossRef] [PubMed]

13. Chen, J.; Wang, W.; Xu, Y.; Zhang, X. Slow-release formulation of a new biological pesticide, pyoluteorin, with mesoporous silica. J. Agric. Food Chem. 2011, 59, 307-311. [CrossRef] [PubMed] 
14. Wen, L.X.; Li, Z.Z.; Zou, H.K.; Liu, A.Q.; Chen, J.F. Controlled release of avermectin from porous hollow silica nanoparticles. Pest Manag. Sci. 2005, 61, 583-590. [CrossRef] [PubMed]

15. Wang, Y.; Cui, H.X.; Sun, C.J.; Zhao, X.; Cui, B. Construction and evaluation of controlled-release delivery system of Abamectin using porous silica nanoparticles as carriers. Nanoscale Res. Lett. 2014, 9, 655-661. [CrossRef] [PubMed]

16. Mas, N.; Galiana, I.; Hurtado, S.; Mondragon, L.; Bernardos, A.; Sancenon, F.; Marcos, M.D.; Amoros, P.; Abril-Utrillas, N.; Martinez-Manez, R.; et al. Enhanced antifungal efficacy of tebuconazole using gated pH-driven mesoporous nanoparticles. Int. J. Nanomed. 2014, 9, 2597-2606.

17. Bernardos, A.; Marina, T.; Zacek, P.; Perez-Esteve, E.; Martinez-Manez, R.; Lhotka, M.; Kourimska, L.; Pulkrabek, J.; Kloucek, P. Antifungal effect of essential oil components against Aspergillus niger when loaded into silica mesoporous supports. J. Sci. Food Agric. 2015, 95, 2824-2831. [CrossRef] [PubMed]

18. Wanyika, H. Sustained release of fungicide metalaxyl by mesoporous silica nanospheres. J. Nanopart Res. 2013, 15, 1831-1839. [CrossRef]

19. Torney, F.; Trewyn, B.G.; Lin, V.S.; Wang, K. Mesoporous silica nanoparticles deliver DNA and chemicals into plants. Nat. Nanotechnol. 2007, 2, 295-300. [CrossRef] [PubMed]

20. Chang, F.P.; Kuang, L.; Huang, C.A.; Jane, W.N.; Hung, Y.; Hsing, Y.i.C.; Mou, C.Y. A simple plant gene delivery system using mesoporous silica nanoparticles as carriers. J. Mater. Chem. B 2013, 1, 5279-5287. [CrossRef]

21. Zhao, P.; Cao, L.; Ma, D.; Zhou, Z.; Huang, Q.; Pan, C. Synthesis of Pyrimethanil-Loaded Mesoporous Silica Nanoparticles and Its Distribution and Dissipation in Cucumber Plants. Molecules 2017, 22, 817-830. [CrossRef] [PubMed]

22. Zhao, P.; Cao, L.; Ma, D.; Zhou, Z.; Huang, Q.; Pan, C. Translocation, distribution and degradation of prochloraz-loaded mesoporous silica nanoparticles in cucumber plants. Nanoscale 2018, 10, 1798-1806. [CrossRef] [PubMed]

23. Brycht, M.; Skrzypek, S.; Robak, J.; Guzsvány, V.; Vajdle, O.; Zbiljić, J.; Nosal-Wiercińska, A.; Guziejewski, D.; Andrijewski, G. Ultra trace level determination of fenoxanil by highly sensitive square wave adsorptive stripping voltammetry in real samples with a renewable silver amalgam film electrode. J. Electroanal. Chem. 2015, 738, 69-76. [CrossRef]

24. Fu, Y.; Zheng, Z.; Wei, P.; Wang, M.; Zhu, G.; Liu, Y. Distribution of thifluzamide, fenoxanil and tebuconazole in rice paddy and dietary risk assessment. Toxicol. Environ. Chem. 2015, 98, 118-127. [CrossRef]

25. Law, J.W.; Ser, H.L.; Khan, T.M.; Chuah, L.H.; Pusparajah, P.; Chan, K.G.; Goh, B.H.; Lee, L.H. The Potential of Streptomyces as Biocontrol Agents against the Rice Blast Fungus, Magnaporthe oryzae (Pyricularia oryzae). Front. Microbiol. 2017, 8, 3. [CrossRef] [PubMed]

26. Srivastava, D.; Shamim, M.; Kumar, M.; Mishra, A.; Pandey, P.; Kumar, D.; Yadav, P.; Siddiqui, M.H.; Singh, K.N. Current Status of Conventional and Molecular Interventions for Blast Resistance in Rice. Rice Sci. 2017, 24, 299-321. [CrossRef]

27. Lu, F.; Wu, S.H.; Hung, Y.; Mou, C.Y. Size effect on cell uptake in well-suspended, uniform mesoporous silica nanoparticles. Small 2009, 5, 1408-1413. [CrossRef] [PubMed]

28. Popat, A.; Liu, J.; Hu, Q.; Kennedy, M.; Peters, B.; Lu, G.Q.; Qiao, S.Z. Adsorption and release of biocides with mesoporous silica nanoparticles. Nanoscale 2012, 4, 970-975. [CrossRef] [PubMed]

29. Cao, L.; Zhang, H.; Cao, C.; Zhang, J.; Li, F.; Huang, Q. Quaternized Chitosan-Capped Mesoporous Silica Nanoparticles as Nanocarriers for Controlled Pesticide Release. Nanomaterials 2016, 6, 126. [CrossRef] [PubMed]

30. Nair, R.; Poulose, A.C.; Nagaoka, Y.; Yoshida, Y.; Maekawa, T.; Kumar, D.S. Uptake of FITC labeled silica nanoparticles and quantum dots by rice seedlings: Effects on seed germination and their potential as biolabels for plants. J. Fluoresc. 2011, 21, 2057-2068. [CrossRef] [PubMed]

31. Sun, D.; Hussain, H.I.; Yi, Z.; Rookes, J.E.; Kong, L.; Cahill, D.M. Mesoporous silica nanoparticles enhance seedling growth and photosynthesis in wheat and lupin. Chemosphere 2016, 152, 81-91. [CrossRef] [PubMed]

32. Gan, Q.; Dai, D.; Yuan, Y.; Qian, J.; Sha, S.; Shi, J.; Liu, C. Effect of size on the cellular endocytosis and controlled release of mesoporous silica nanoparticles for intracellular delivery. Biomed. Microdevices 2012, 14, 259-270. [CrossRef] [PubMed]

(C) 2018 by the authors. Licensee MDPI, Basel, Switzerland. This article is an open access article distributed under the terms and conditions of the Creative Commons Attribution (CC BY) license (http://creativecommons.org/licenses/by/4.0/). 